\title{
IDENTIFICAÇÃO, DESCRIÇÃO E DATAÇÃO DO CÓDICE GREGO NEOTESTAMENTÁRIO DA BIBLIOTECA NACIONAL DO RIO DE JANEIRO (MANUSCRITO 2437)
}

Paulo José Benício*

RESUMO:

Este trabalho trata do mais antigo manuscrito pertencente à Biblioteca Nacional do Rio de Janeiro: um códice em pergaminho, escrito com caracteres minúsculos, contendo os quatro Evangelhos e datado do século XII. Ele foi doado àquela instituição em 1912, por João Pandiá Calógeras, conhecido intelectual e politico brasileiro, de ascendência grega. Em 1953, alicerçado em informações concedidas por Bruce Metzger, Kurt Aland repertoriou-o, atribuindo-lhe o número 2437.

PALAVRAS-CHAVE: evangelho, códice, manuscrito, pergaminho.

0 Evangelho (segundo Mateus, Marcos, Lucas e João, nessa seqüência) em posse da Biblioteca Nacional do Rio de Janeiro, por se tratar do mais antigo manuscrito e do único códice em língua grega de cuja existência se tem conhecimento na América Latina, é um documento ímpar. Isso devido ao seu valor histórico: ele é mais um testemunho dos Evangelhos; ademais, sob o ângulo da crítica genética (o texto que cada documento traz constitui uma variante peculiar), o minúsculo 2437 tem-se constituído como uma leitura particular desses escritos, no Brasil, desde o momento da sua doação. À Biblioteca Nacional foi presenteado, provavelmente em 1912, pelo erudito e político brasileiro, de origem grega, João Pandiá Calógeras (filho de Michel Calógeras e Júlia Rali Calógeras).

0 preeminente especialista em crítica textual do Novo Testamento grego, Bruce M. Metzger, foi quem, no ano de 1952, pela primeira vez, o descreveu (cf.

| Doutor em Letras: Estudos Literários (Área de concentração: Literatura Comparada), 2002. 


\section{EMTESE}

Belo Horizonte, v. 7, p. I-I I 0, dez. 2003

Metzger, 1952: 5-9). Em 1953, fundamentado nas informações enviadas, em carta daquele ano, por Metzger, Kurt Aland repertoriou-o, atribuindo-1he o número 2437 (cf. Aland, 1953). Em 1954, o mesmo Aland, ao publicar a quinta listagem de manuscritos gregos neotestamentários, registrou o da Biblioteca Nacional (cf. Aland, 1954: 195). Em 1958, com base nas publicações de Aland, Marcel Richard incluiu este documento no seu repertório das bibliotecas e dos catálogos de manuscritos gregos (cf. Richard, 1958: 196). Em 1989, na segunda edição do seu livro sobre a crítica textual do Novo Testamento grego, Kurt Aland e Barbara Aland arrolaram este códice (cf. Aland \& Aland, 1989: 139-141). B. P. Bittencourt, em 1993, na terceira edição da sua obra a respeito do cânon, da língua e do texto neotestamentários pincelou uma nota concernente ao Evangelho grego ${ }^{1}$. Em 1996, Paulo Herkenhoff também dele fez menção, em seu livro respeitante à coleção da Biblioteca Nacional, reproduzindo, inclusive, a título de ilustração, uma de suas páginas². Aquele foi o ano em que o Laboratório de Restauração da Biblioteca Nacional recuperou o volume, dando-lhe tratamento adequado. Finalmente, em 1997, um trabalho referente ao documento 2437 foi trazido a lume por Jacyntho Lins Brandão, Professor Titular de Língua e Literatura Grega da Universidade Federal de Minas Gerais (cf. Brandão, 1997: 4-5).

0 manuscrito 2437 foi copiado em fólios pergamináceos (exceto os quatro últimos, cujo material é o papel), de média qualidade, medindo $21,4 \times 16 \mathrm{~cm}$ (com variações de até $0,5 \mathrm{~cm}$, para mais e para menos). Recentemente numerados a lápis, estendendo-se de 1 a 233, na margem inferior do códice, compõe-se de 31 fascículos ${ }^{3}$. Observa Ana Virgínia Pinheiro que "o reto do primeiro fólio e o verso do último, em cada fascículo, são impostos pelo lado da carne, o que identifica 2437 como sendo de origem grega ortodoxa" (Pinheiro, artigo não publicado: 6).

A encadernação atual do códice, montada em estilo de época, em pergaminho flexível, inteira, com nervos em pele de cabra e garras em couro, é tipicamente monacal (cf. Pinheiro, artigo não publicado: 7).

Salvo nos fólios de papel, a escrita, em forma de letra minúscula, ocupa uma mancha (a parte escrita do suporte, no espaço coberto pela tinta) de 14,4 × 9,5 cm, para mais e para menos, excluindo o tamanho das letras maiúsculas delineadas na margem vertical esquerda, regulada em cerca de $0,5 \mathrm{~cm}$. A grafia é bastante regular e legível. 
Em vermelho, foram escritos enfeites, títulos, letras iniciais e auxîlios ao leitor, caso dos famosos cânones eusebianos (tabelas organizadas com a finalidade de localizar passagens paralelas nos Evangelhos, as quais foram preparadas por Eusébio, c. 265-339, Bispo de Cesaréia). Também, nesse tom, foram escritos os

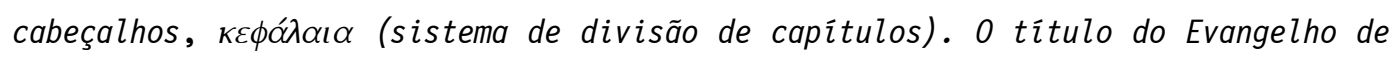
acordo com Marcos encontra-se no fólio 53 (reto), onde se lê: ЕҮАГГЕ $\Lambda$ ION KATA MAPKON TO $\triangle$ EYTEPO (N), EVANGELHO DE ACORDO COM MARCOS, O SEGUNDO.

0 texto, em cor parda, acha-se disposto numa única coluna composta de 24 linhas, excetuando-se os fólios iniciais dos Evangelhos de Marcos, Lucas e João, que apresentam 19 linhas de texto ${ }^{4}$, além de uma faixa retangular, no alto, com decoração geométrica, e do título, escrito, logo abaixo, em maiúsculas. 0 número de linhas ocupado nos últimos fólios de cada um dos Evangelhos é variado - em Marcos, por exemp1o, somam-se 10. Ainda no que concerne a linhas, Ana Virgínia Pinheiro observou que "foram pautadas por punção e cinzelamento, com ponta seca, o que se pode verificar pelas perfurações, nas zonas extremas das margens de cada fólio e pelo risco lavrado da pauta" (Pinheiro, artigo não publicado: 9). Esta afirmação é valiosa para a datação do códice, uma vez que a técnica descrita por ela foi utilizada até o século XII.

Tudo parece indicar que a escrita do texto principal é decorrente do trabalho de uma única mão (ainda que anotações marginais, indicando trechos destinados a leituras litúrgicas ou registrando variantes, tenham sido elaboradas por terceiros). 0 copista empregou sistematicamente os espíritos e os acentos; em certos momentos, fez uso do trema sobre iotas e ípsilons iniciais. Ele não somente utilizou o ponto acima e abaixo da linha como também a vírgula. Em nenhuma oportunidade, grafou 0 iota subscrito, o que constitui um outro importante indício para datação (século XII), já que o testemunho mais remoto desse uso, em se tratando dos escritos neotestamentários, remontaria, de acordo com Caspar R. Gregory, a 1160 (cf. Gregory, 1894: 109).

Observa-se também o registro dos cabeçalhos do Evangelho segundo Marcos nos fólios 52 (reto) / 52 (verso); nos fólios 96 (reto) / 96 (verso) e 97 (reto) / 97 (verso), encontram-se os de Lucas. 


\section{EMTESE}

Belo Horizonte, v. 7, p. I-I I0, dez. 2003

A presença do cognominado final longo de Marcos (16.9-20) como parte integrante do texto é um ponto de destaque no códice da Biblioteca Nacional. Nesta perícope, além das notas marginais (cf. fólio 95, reto, linhas 17-24), chama a atenção a presença de um espaço em branco, com comprimento de $3,5 \mathrm{~cm}$, entre a

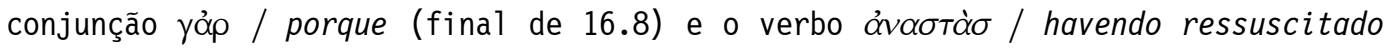
(início de 16.9), na linha 20 (cf. fólio 96, reto). Já que um espaço com este tamanho (entre trechos) não aparece em nenhum outro lugar do manuscrito 2437, é muito provável ser esta mais uma indicação da inserção posterior de 16.9-20 à conclusão abrupta (16.8) do Evangelho.

No que se refere à distribuição de Marcos 16.9-20 nos fólios, verificase a seguinte curiosidade: no 96 (reto), as linhas 7-10 estão centralizadas e assumem uma extensão menor que todas as outras do texto. Além disso, nas 1inhas 910, demonstrando a discreta ornamentação do códice, foram desenhadas três cruzes gregas, sugerindo o contorno de um prato com uma cavidade no meio, onde seriam consagradas as hóstias nas celebrações litúrgicas tanto dos ritos orientais quanto da Igreja Latina - o que poderia consistir uma alusão à obra expiatória de Cristo, ênfase do Segundo Evangelho (cf. Pinheiro, artigo não publicado: 10-11).

Por fim, deve-se registrar uma troca de posição importante. No décimo primeiro fascículo, o terceiro fólio, juntamente com o sexto, seu correspondente, pertencem ao Evangelho de João, sendo sua numeração em algarismos gregos relativa a este Evangelho (fólios $l \gamma^{\prime}$ e $\kappa^{\prime}, 13$ e 20, respectivamente); o bifólio deslocado de Marcos encontra-se em João, no vigésimo quarto fascículo, ocupando a parte exterior; a numeração em algarismos arábicos ignora o deslocamento, recebendo os dois fólios os números 86 e 83 , respectivamente. 0 problema é que a encadernação foi feita invertidamente: o fólio $\lambda \delta^{\prime}$ (34) aparece antes do $\lambda \alpha^{\prime}$ (31), correspondendo aos atuais, 185 e 192. 
NOTAS:

1. Inadvertidamente, o minúsculo dos Quatro Evangelhos é apontado como um manuscrito uncial do Evangelho segundo Marcos. Cf. Bittencourt, 1993: 92.

2. Este autor, todavia, cometeu erros na análise do documento - em primeiro lugar, não se trata de um evangeliário (1ivro que encerra fragmentos dos Evangelhos para as celebrações litúrgicas diárias e de determinadas épocas do ano nas igrejas cristãs, desde o surgimento da Comunidade Primitiva até hoje), mas sim de um volume contendo os quatro Evangelhos (Mateus, Marcos, Lucas e João). Em segundo lugar, o manuscrito não foi redigido em letras semi-unciais, mas em minúsculas gregas. Cf. Herrkenhoff, 1996: 24.

3. Metzger alude a 234 fólios. Resta saber se, entre 1952 e 1996, um fólio foi perdido ou danificado. Cf. Metzger, 1952: 7.

4. Mateus foi omitido por lhe faltarem os dezesseis fólios iniciais, os quais conteriam o começo do Evangelho até o capítulo 9, versículo 17.

ABSTRACT :

This paper examines the most ancient manuscript that belongs to the Rio de Janeiro National Library - a twelfthcentury parchment codex, written in minuscules, which contains the four gospels. It was donated to that institution in 1912, by João Pandiá Calógeras, a wellknown Brazilian intellectual and politician of Greek origin. In 1953, based on pieces of information given by Bruce Metzger, Kurt Aland cataloged it, ascribing the number 2437 to it.

KEY WORDS: gospel, codex, manuscript, parchment. 
ALAND, K. Zur Liste der Griechischen Neutestamentlichen Handschriften. Theologische Literaturzeitung, $t$. LXXVIII, col. 465-496, 1953.

- Zur Liste der Neutestamentlicher Handschriften $\bar{V}$. Zeitschrift für die Neutestamentliche Wissenschaft und die Kunde der Alteren Kirche, t. XLV, p. 179-217, 1954 .

- ALAND, B. Der Text des Neuen Testaments Eiführung in die Wissenschaftlichen Ausgaben sowie in Theorie und Praxis der Modernen Textkritik. 2. Aufl. Stuttgart: Deutsche Bibelgesellschaft, 1989.

BITTENCOURT, B. P. O novo testamento: metodologia da pesquisa textual. 3.ed. Rio de Janeiro: JUERP, 1993.

BRANDÃO, J. L. 0 evangelho grego da Biblioteca Nacional do Rio de Janeiro (manuscrito em minúsculas gregas do novo testamento $\mathrm{n}$. 2347). Boletim Latino - americano de estudos clássicos, ano IV/V, n.4/5, p. 45-48, 1997.

GREGORY, C. R. Novum testamentum graece ad antiquissimos testes denuo recensuit apparatum criticum apposuit Constantinus Tischendorf editio octava critica maior. v. 3. (Prolegomena). Lipsie: J. C. Hinrichs, 1894.

HERRKENHOFF, P. Biblioteca nacional: a história de uma coleção. Rio de Janeiro: Salamandra, 1996.

METZGER, B. M. Um manuscrito grego dos quatro evangelhos na biblioteca nacional do Rio de Janeiro. Revista teológica do seminário presbiteriano do sul, n.2. (nova fase), p. 112-121, 1952.

PINHEIRO, Ana Virgínia. O evangelho manuscrito em grego existente no acervo da Biblioteca Nacional brasileira: aspectos codicológicos (trabalho não publicado).

RICHARD, M. Répertoire des bibliothèques et des catalogues des manuscripts grecs. 2.ed. Paris: CNRS, 1958. 